\title{
PROMOTING INTERCULTURAL EXCHANGE THROUGH A CORNERSTONE ENGINEERING DESIGN PROJECT
}

\author{
Brian Dick ${ }^{1}$ and Thai Son Nguyen ${ }^{2}$ \\ ${ }^{1}$ Faculty of Science and Technology, Vancouver Island University \\ ${ }^{2}$ School of Engineering and Technology, Tra Vinh University \\ brian.dick@viu.ca, thaison@tvu.edu.vn
}

\begin{abstract}
First-year engineering students at Vancouver Island University in Canada and second-year engineering students at Tra Vinh University in Vietnam have been brought together to work on a cooperative cornerstone design project as a means to introduce intercultural competencies early in the students' academic experience. Student teams at each institution were partnered, whereby a design proposal developed by a team at one institution was constructed by their partner team at the other institution. Each team provided stakeholder input early in the design stage, and team pairs established a change management structure to respond to challenges occurring during the construction phase of the project.
\end{abstract}

We explore the challenges and successes of the students experience as they navigated the linguistic, cultural, technical, and geographic barriers towards successfully completing this major design project.

Keywords: Intercultural Communication, International Cornerstone Design Project, International Collaboration, Intercultural Competencies, First-year Engineering Curriculum

\section{INTRODUCTION}

\subsection{Motivation for an Intercultural Design Project}

Globalization has increasingly demanded that engineering graduates exhibit intercultural competencies in addition to the graduate attributes required by the Canadian Engineering Accreditation Board (CEAB) [10]. Although there is much study on how these competencies are defined and cultivated within engineering education $[1,2,5,8,9]$, Hofstede [4] provides a useful frame to the concept: the ability to participate in the social life of people who live according to different unwritten rules. According to Parkinson [8], industrial leaders identify global competence, a term used synonymously with intercultural competency, as being highly regarded to essential for a graduate of engineering. A graduate of today should expect that even if their career path does not physically take them outside of their home country's borders, they most likely will be part of a team which may draw a multidisciplinary membership across a broad range of cultural, social-economic and linguistic backgrounds, and will be expected to translate ideas into reality for users who have diverse perspectives on the world.

Academic institutions have grown considerably more diverse in their student populations in recent years (for example, the international student population of Vancouver Island University has increased from 12\% to $18 \%$ of the total student body over the last 5 years [11]; other post-secondary institutions in $\mathrm{BC}$ have seen even more growth). Yet intercultural competence development requires that students "go beyond interacting with classroom peers to have collaborative work experiences with people who have been raised, educated, and living [emphasis added] in the host country" [1]. Capstone design projects have long been an essential component of most engineering programs, and have been shown to provide an effective means for enhancing students' intercultural attributes through progression towards a shared goal. As cultural intelligence is believed to develop over time and in several stages [2], there may be value introducing students to intercultural activities within cornerstone design projects earlier in their academic careers.

\subsection{Background}

Vancouver Island University (VIU) in Canada and Tra Vinh University (TVU) in Vietnam have had a long-term relationship, which began when VIU (then known as Malaspina University-College) participated in a Canadawide consortium to establish the first community college in Tra Vinh Province under a Canadian International Development Agency (CIDA) grant. Tra Vinh Community College was upgraded to a full university in 2006, while Malaspina University-College transitioned to a full teaching university under the name Vancouver Island University in 2008; the partnership between the engineering programs at VIU and TVU was established in 2009. 
While VIU and TVU differ in their academic scope, they are similar in that they are both located in semi-rural communities with a relatively low visible minority population. TVU offers both bachelor and technical diplomas in engineering, and has established international partnerships to co-supervise a limited number of graduate students. VIU offers the Fundamentals of Engineering certificate which provides the first-year curriculum for the University of British Columbia - Point Grey campus (UBC-V), the University of Victoria (UVic), and Simon Fraser University - Burnaby campus (SFU-B). Students completing their first year at VIU are required to complete their engineering education at one of these three schools under established transfer agreements.

\subsection{Project Scope}

It has been a long-term goal of both VIU and TVU to better establish student-to-student interactions to enhance the international experience of both student groups. Both institutions emphasize project-based learning [3] early in their students' academic experience, which was recognized as an opportunity to build a connection between the two groups.

Several barriers exist between the two institutions and its students including language, cultural, socio-economic, technical, and geographic (represented by a 15-hour time zone difference between the two institutions). These barriers are not unique to the academic realm; having students begin to develop skills necessary to navigate the above challenges to create a deliverable product is of value for their professional engineering careers.

Of these barriers, it was initially believed that language would be the most prominent. For example, Tra Vinh University does emphasize a set number of hours of English language instruction as part of its engineering curriculum; however, exposure to native English speakers is limited. VIU students did not have any Vietnamese language background.

Cultural expression and social-economic differences are also believed to have an impact on how these two student groups interact: A preliminary comparison of the same brainstorming exercise undertaken with students at both institutions showed different approaches by each group in terms of determining and weighing decision criteria to evaluate potential solutions.

One of the goals of this project was to monitor and evaluate how students perceived and responded to these barriers over the project development. It was also of interest to determine if introducing students early to intercultural interactions encourages their desire to further participate in these experiences later in their academic careers.

\section{METHOLOLOGY}

\subsection{Student Background}

Volunteers to take part in this project were sought from students enrolled in the Fundamentals of Engineering certificate program at Vancouver Island University and the $2^{\text {nd }}$ year of an Engineering degree or diploma program at Tra Vinh University. The $2^{\text {nd }}$ year was chosen at TVU as it was believed by their instructors that these students had stronger English language skills and were better able to communicate with the 1st year VIU students, while still maintaining some consistency in technical background between the two groups.

At VIU, the Fundamentals of Engineering certificate program consists of two sequential, project-based design courses offered in the Fall and Spring terms. These courses are referred to as ENGR 112 and ENGR 121 respectively. ENGR 112 and 121 introduce engineering design, the engineering profession, and engineering ethics, through team- and project-based learning, and, collectively, are consistent with the first-year design curriculum at both UBC-V [7] and UVic [6]. In 2016, all students enrolled in ENGR 112 attended a seminar that provided a perspective on Tra Vinh University, its students and its local community, a brief description of the proposed project framework, and concluded with a request student participants. The intercultural design project, itself, took place in 2017 as part of ENGR 121, a course consisting of three, two-hour lab sections of sixteen students each as well as two, one-hour lecture/seminar periods per week that are common to all students. All students who agreed to participate in the project were enrolled in the same lab section of ENGR 121, provided that they fulfilled the prerequisites for the course. These students self-selected into four groups of four students, and engaged with the instructor in an in-class conversation on intercultural interactions, and tools for overcoming linguistic barriers. As the project took place as part of the regular design curriculum, the remaining two lab sections undertook a similar design project framework, albeit without the intercultural interaction component.

At Tra Vinh University, instructors identified potential students from which fourteen $2^{\text {nd }}$ year students enrolled in either bachelor programs (Cybernetic and Automatic Engineering and Electrical and Electronic Engineering) or diploma programs (College of Electrical and Electronic Engineering) volunteered to take part in the project. All bachelor program students were also members of the Institute of Electrical and Electronics Engineers (IEEE) student branch. The TVU students were grouped into four teams (numbering from three to five members). To help ensure consistency in student background, the VIU and TVU instructors undertook a study of both the TVU and VIU design curriculum. As a result of this study, the VIU 
instructor was invited to provide in-person seminars on the engineering design process, formal decision tools, and a general overview of critical thinking to the TVU student volunteers. Although this design project did not take place as a formal part of the TVU engineering curriculum, participating students could use the activity as credit towards their Introduction to Microcontroller course work.

\subsection{Major Design Project Framework}

Student teams at both TVU and VIU were presented a scenario in which they were required to design a replacement, moveable bridge in the other institution's community: TVU students were to design a replacement for the Johnson St. bridge in Victoria, BC, while VIU students were to design a replacement to the Long Binh \#3 bridge in Tra Vinh City. Student teams at each institution created a design proposal, which was exchanged with a student team at the other institution to be subsequently built as a model.

The major project was split into design and construction phases, consisting of a total of five stages spread over the entire term (approximately three months). The overall project stage progression was loosely based on a UVic ENGR 120 major project offered in 2012.

The design phase consisted of two stages:

Stage \#1 - Each member of the student design team worked individually and independently to evaluate a specific moveable bridge type and determine its pros and cons. An engineering drawing and/or computer aided drawing (CAD) of their proposed bridge structure was produced. Students at each institution were encouraged to engage with each other as project stakeholders through an on-line blog forum.

Stage \#2 - Additional project requirements were provided to the student teams at both TVU and VIU through a common Dropbox folder. Each design team evaluated the bridge structures produced by their members in Stage \#1, and determined a best design solution through a formal decision process. A sufficiently detailed proposal for building a bridge model was prepared in English, which was subsequently exchanged with a randomly selected team at the partner institution.

Upon receipt of their partner team's proposal, each student team (i.e. now considered a contractor team) was required to build a bridge model. This construction phase took place in three stages:

Stage \#3 -- Student teams built the structural aspect of the proposed bridge design. A progress report was produced at this stage and testing of the structural aspect of the bridge model was undertaken.

Stage \#4 -- Student teams designed and implemented the required sensors and actuators for the project. A progress report was produced at this stage.

Stage \#5 -- Student teams integrated the sensors and actuators into the bridge structure. A final report on their project was produced including an oral and community presentation.

The relationship between project phases and stages is illustrated in Figure 1.

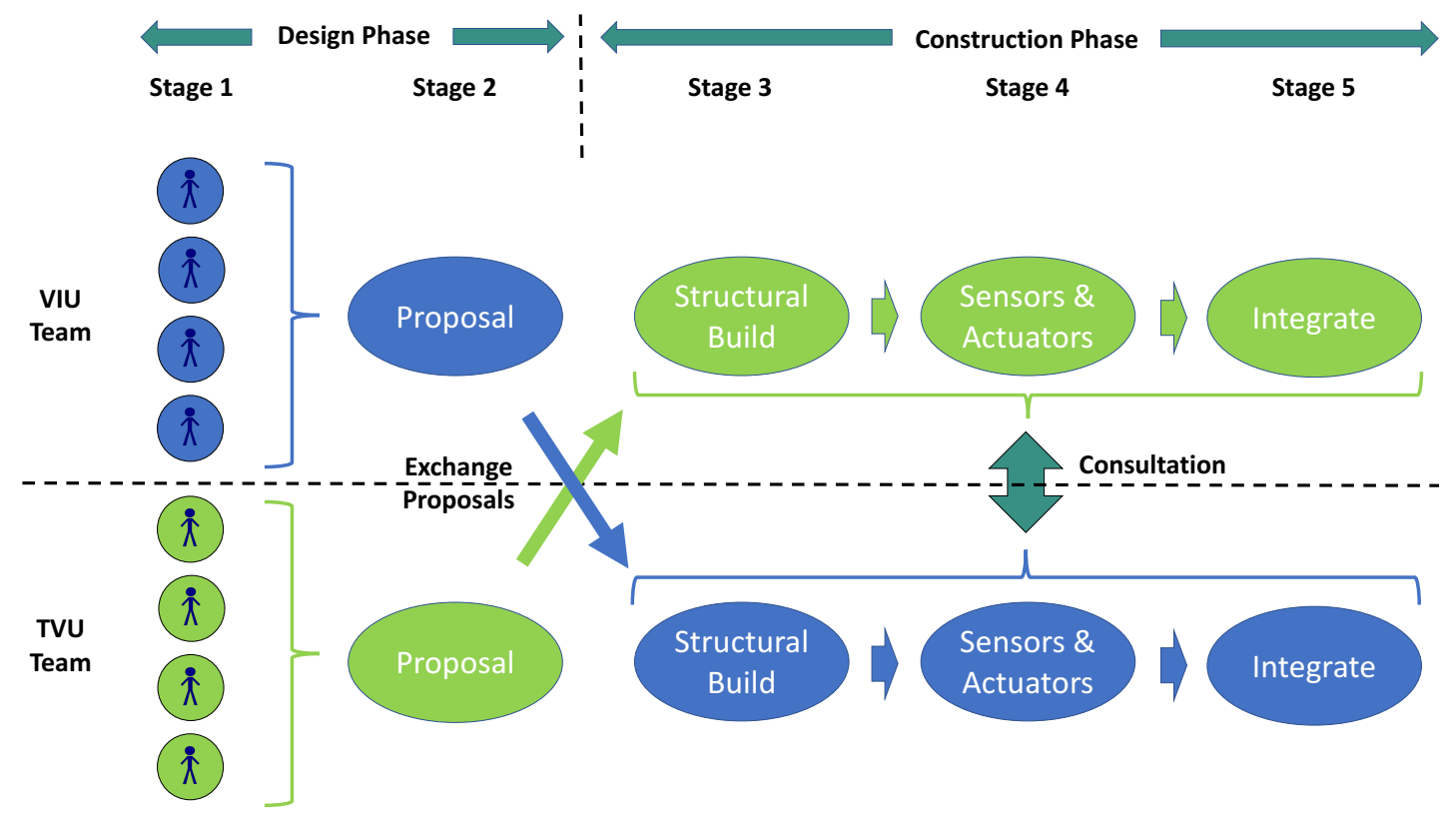

Figure 1. Cornerstone Design Project Phases and Stages. 
From Stage \#3 to \#5, student teams were also required to maintain a change management process to ensure that any deviations from the original proposal were agreed to by both the design and the contractor teams and fully documented. It was expected (and encouraged) that both student teams would assist each other with troubleshooting design solutions. Suggested tools (e.g. Skype, Facebook, Google docs) for inter-team communication were suggested but no specific tool was required. Students were expected to determine their most convenient channel for efficient and effective communication.

At each Stage, all team members were required to prepare an independent and confidential peer review assessment. The team lead, in consultation with his/her group, was also required to prepare a team-pair interaction assessment. These assessments were provided to the primary instructor at each institution as part of their Stage deliverables and used to help evaluate the group dynamics of each team and between teams during the term.

\section{RESULTS AND DISCUSSION}

An exit assessment of students was conducted during their final week of the term in the form of both a short survey focused on their intercultural experience, as well as a reflection exercise on the design project as a whole. This feedback was primarily drawn from students at VIU, while a more in-depth study of feedback from TVU students is to be conducted in the coming months.

\subsection{Intercultural Experience Survey}

The intercultural experience survey was distributed to students through their on-line learning environment, and answers were anonymous. For those questions that were qualitative, the analysis is a result of the researcher's interpretation of the data.

\section{Intercultural Experience}

This survey found that nearly all participating students had not travelled to South-East Asia (86\%), and that a majority self-assessed as having little or no contact with students of differing cultures $(56 \%)$.

Students generally indicated that they volunteered to take part in the project through curiosity and the opportunity to experience a more typical engineering working environment. One student answered:

I felt like it would be an interesting experience, as well as a rare opportunity in first-year engineering.

Students seem to provide responses that contradicted each other when asked about what surprised them the most during the project, and what was their greatest challenge. Most students indicated that the ease with which they were able to communicate was their biggest surprise, yet, conversely, they also indicated language barrier (most often) as their greatest challenge, particularly when it came to face-to-face interactions:

\section{The greatest challenge I found was the inability to have a face to face conversation with them, as they didn't feel comfortable skyping in English.}

The VIU students had more varied responses when it came to their description of the main cultural difference between the two teams ranging from the desire of the TVU students to always speak through their team lead, when the VIU students often wanted to speak collectively, to TVU students tending to want to stick to more 'traditional' designs and styles, to "Honestly, it seemed like I was talking to another student here at VIU who didn't have english [sic] as their first language. I couldn't tell any cultural difference"

\section{Team-Pair Interactions}

A few of the questions related to how often the teams communicated and through what channel. The survey found that all the teams used Facebook messenger, while supplementing with e-mail (42\%), Skype (29\%), and Google Docs $(29 \%)$. One student did request that if this project were to be repeated that a dedicated virtual channel be established as they preferred to keep "school stuff' off of their personal Facebook page.

Communication between the teams occurred quite frequently, particularly in Stage \#3 through \#5 once the team-pairs were established. All student teams interacted at least 10 times over the project term, while 58\% interacted more than 15 times. Indeed, at least one of the teams indicated that they interacted with their paired team every day. Most of this communication was through the team leads which caused some students to express that they wished the intercultural communication experience was more broadly shared.

Motivation to Pursue Continued Intercultural Experiences

For the last two questions of the survey, students were asked to self-assess their improved ability to work with people from other cultures and their desire to participate in further intercultural experiences. Their responses indicated that $86 \%$ of students felt that their experience on this project either slightly, or greatly improved their ability to work with people from other cultures. Likely more relevant for long term improvement of the students' intercultural competencies, $43 \%$ of students indicated that they were much more likely to participate in intercultural and/or international projects during their academic careers. 
A further $29 \%$ indicated that they were more likely to participate in these activities. Only $29 \%$ indicated that this project has had no effect on their desire to participate in intercultural/international activities, and no students indicated that this project decreased their desire to do so.

\subsection{Student Written Responses}

Student feedback from their reflection exercise and the final team-pair interaction assessment was used to reflect on how the relationship between student groups evolved over the course of the project.

Students soon identified and learned to adapt to the language barrier between the two groups:

Our only real issue was conversing with the other team, as English is not their first language and sometimes things are misinterpreted or misunderstood, leading us to make errors ... Our communication skills are getting better, as we are able to solve problems through messages more efficiently now than we could before.

Students developed their own process for improving communication efficiencies such as: using simple language, exchanging videos and/or pictures to aid in describing a concept/idea, and pairing request for changes with a solution to save time between responses (due to the $15 \mathrm{hr}$ time difference between VIU and TVU):

\section{...he said that he prefers to speak through written communication as it is easier for him to understand and response appropriate due to the language barrier.}

The time difference was often indicated as a barrier in the students' written responses, especially when they required a change request approval when under deadline pressure. The 15-hr time difference sometimes forced them to stop work and wait for a reply:

The English barrier wasn't bad as google translate can translate from Vietnamese to English and back over quite well. It was a lot of "using the right words" when sending messages. The biggest barrier was definitely the time zone difference; however, the team lead from Vietnam always stayed up super late so that was a huge help. It was a lot of fun talking back and forth with them.

There is a general sense from all groups that communication between teams has been respectful and the tone positive when speaking about the other group and the project as a whole.
At first, communication with the TVU students appeared daunting. We could not speak Vietnamese, and they were not fluent in English. One of our first meetings was not very successful since it was nearly impossible to communicate orally. Fortunately, the TVU students' written English was very good, and we were able to effectively communicate through text and diagrams. Their overall enthusiasm to work together make it easier to communicate and meet.

\section{CONCLUSIONS}

This study demonstrated that students can be positively impacted by early exposure to intercultural partnerships, which can be used to encourage them to further pursue these partnerships over their academic and professional careers. Students demonstrated an increased understanding of how best to overcome cultural, socialeconomic, linguistic, and time-zone difference barriers to successfully complete an engineering project. Indeed, although language was often cited by students as the most significant barrier at the start of the project, most found that the importance of this barrier diminished considerably as the project developed.

Students did identify several features of the project that could be improved including encouraging face-to-face interactions, broadening the experience beyond primarily the team leads, and establishing an official communication portal outside of Facebook. In the coming months, the TVU student perspective on the project will be available and it will be interesting to evaluate how the two groups compare in their experiences.

Generally, however, students expressed positive feelings over their experience and the following statement is typical of the feedback received:

Working with the TVU students was an awesome learning experience. It gave us a good example of what happens in the real world, as we had no physical contact with them, it was strictly messenger. Aside from working with the Vietnamese students, the idea of swapping proposals in general was an awesome change to the usual way it is run. We found ourselves having that extra challenge of managing two bridges at the same time, which was a lot of fun.

\section{Acknowledgements}

The authors would like to thank Dr. Hoa Nguyen Minh, Khoi Huynh Cong, Phuc Huu Dang, Tan Nguyen Thanh, and Khanh Nghi Vinh for providing support to the TVU student teams during this project. We would also like to 
thank Dr. Bill Roberson at the VIU Centre for Innovation and Excellence in Learning for his assistance in the initial framing of the team-based approach. Finally, we deeply appreciate the financial support provided by Herold Engineering Inc and the VIU Global Engagement Program Development grant which helped allow this project to go forward.

\section{References}

[1] Ali, N. B., Zhu, S., Behdinan, K., "Benefits and Barriers to International Collaboration for Capstone Design Course," Proc. Canadian Engineering Education Association CEEA16 Conf., (Halifax, NS; 19-22 June 2016), Paper 120.

[2] Del Vitto, C., "Cross-Cultural "Soft Skills" and the Global Engineer: Corporate Best Practices and Trainer Methodologies," Online Journal for Global Engineering Education, , vol. 3, iss. 1, article 1 (2008)

[3] Dym, C. L., Agogino, A. M., Eris, O., Frey, D. D., Leifer, L. J., "Engineering Design Thinking, Teaching and Learning" $J$.

Eng. Education, 103 (2005)

[4] Hofstede, G.J., The Moral Circle in Intercultural Competence, in Deardoff, D.K. (Ed.), The Sage Handbook for Intercultural Competence pg 85-99, Sage Publications, Inc, 2009 \{ISBN: 978-1-4129-6045-8\}

[5] LaFave, J. M., Kang, H-S., Kaiser, D., "Cultivating Intercultural Competencies for Civil Engineering Students in the Era of Globalization: Case Study," J. Prof. Issues Eng. Educ.

Pract., 141, 3 (2015)
[6] McGuire, M., Li, K. F., Gebali, F., "Teaching Design to First-Year Engineering Students," in Proc. Canadian Engineering Education Association CEEA15 Conf., (Hamilton, ON; 31-May to 03-Jun 2015), Paper 001.

[7] Ostafichuk, P. M., Jaeger, C.P., Nakane, J., Nesbit, S., Ellis, N., Sibley, J., "Redesigning the UBC First Year Introduction to Engineering: Successes and Challenges," in Proc. Canadian Engineering Education Association CEEA16 Conf., (Halifax, NS; 19-22 June 2016), Paper 135.

[8] Parkinson, A., "The Rationale for Developing Global Competence," Online Journal for Global Engineering Education, , vol. 4, iss. 2, article 2 (2009)

[9] Yu, H, "A Study of Engineering Students' Intercultural Competence and Its Implications for Teaching," IEEE Trans. Prof. Comm. 55 (2), 185 (2012)

[10] 2016 Accreditation Criteria and Procedures. Canadian Engineering Accreditation Board (CEAB), 2016 \{ISSN 17088054\} Available as of Apr 26, 2017 from engineerscanada.ca/sites/default/files/accreditation-criteriaprocedures-2016-final.pdf

[11] 2016-2017 Environmental Scan Available as of Apr 26, 2017 from:

www2.viu.ca/budget/documents/2016_2017EnviroScan.pdf 